\title{
A Proposed Educational-Administrative Vision for Activating the Role of Educational Media in Jordanian Secondary Public Schools in Addressing the Intellectual and Cultural Challenges
}

\author{
Dr. Roweida Zuhir Mohammed Al Abed Prof. Rateb Salameh Al-Soud
}

\begin{abstract}
The present study aimed to offer a proposed educational-administrative vision for activating the role of educational media in Jordanian secondary public schools in addressing the intellectual and cultural challenges. The population consists from all the Jordanian secondary public school principals (i.e. 1227 female and male principals). The sample consists from 127 female and male principals. It represents $10 \%$ of the population. A developmental survey-based approach was adopted. It was found that educational media plays moderate role in addressing the intellectual and cultural challenges in Jordanian secondary public schools. There isn't any statistically significant difference between the respondents' attitudes which can be attributed to (gender, or academic qualification). However, there are statistically significant differences between the respondents' attitudes which can be attributed to experiences for the favour of the ones who have 10 years or more. Based on the study's results, the researchers proposed an educational-administrative vision for activating the role of educational media in Jordanian secondary public schools in addressing the intellectual and cultural challenges. The applicability of this vision was examined. Keywords: Educational media, intellectual and cultural challenges, secondary public schools, Jordan DOI: $10.7176 / \mathrm{JEP} / 11-33-13$
\end{abstract}

Publication date: November $30^{\text {th }} 2020$

\section{Introduction:}

Education plays a major role in making reforms in political, economic, social, cultural and intellectual aspects. It play a significant role in raising a citizen whose personality is balanced in cognitive, and emotional aspects. It plays a significant role in developing one's skills. It plays a significant role in enabling one to handle the $21^{\text {st }}$ century intellectual and cultural challenges. To deliver effective education, there must be effective collaboration between various educational entities (e.g. families, schools, universities, worship houses, media channels and etc.).

Media today is considered a double edged sword. To illustrate more, it may be used in a manner that benefits the members of the society or poses a threat to them. During the third millennium, developed countries have been seeking to control developing countries in intellectual areas. They have been seeking to do that through promoting the ideas and cultures of the invading countries. They have been seeking to do that through making major changes to the cultures, behaviors and ideas of the countries being invaded. The invading countries target culture, because culture plays a significant role in determining the current and future behaviors of people.

Similar to economic and political issues, cultural issues became significant on the global level. They have become so due to the emergence of technological issues. Technologies are used by the governments that have been seeking to invade countries culturally. To meet such goals, they use technologies that target all people in general and youth in particular. Youth are targeted because their personalities are easier to change (Madkour, 2003).

The relationship between media and education is strong and dynamic. That is because educational and media institutions play a significant role in educating people. The latter institutions play a significant role in socialization, and developing people intellectually (Khadr, 2018).

The term (educational media) emerged. It refers to the media that aims at providing students with valid information and facts in order to develop the students' emotions and personalities. It aims at developing students in intellectual, cultural, social and intellectual aspects. It aims at meeting specific educational goals. The goals of the educational media in the Jordanian Ministry of Education include: providing students with valid information and strengthening the social bonds between the members of the society. They include: providing students with knowledge about the reality, history and achievements of their society. They include: improving the quality of education and improving the outcomes of educational institutions. They include: improving the effectiveness of the curricula in meeting the intended goals. They include: promoting a sense of belonging and loyalty within people towards their homeland. They include: informing people about their rights and duties and encouraging people to do good behaviors. They include: emphasizing good behaviors and promoting awareness about the problems faced by youth. They include: addressing the latter problems and issues related to youth. They include: promoting democracy-related values among people. They include: encouraging people to express their views and respect the ones who have different opinions. They include: promoting religious and ethical principles and values (Bosfor et al., 2011).

There are several challenges that face the cultural identities of people in the Arab world. Such challenges include: globalization, information revolution, extremism, and decline in the ethics (Al-Raqab, 2007). To address 
such challenges, people must be aware that cultural identity is the most important thing that distinguishes any society from other societies. For instance, cultural identity determines the ambitions and behaviors of people. Due to the significance of cultural identity, it must be based on fixed social and ethical principles (Najm, 2004).

During the contemporary age, technological developments are made in an ongoing manner. Due to having rapid technological developments, wars are initiated today in intellectual areas instead of using firearms and weapons. Through the intellectual wars, all types of media channels are used. They include: social media and visual, readable and audio media. Due to having intellectual wars, awareness must be promoted among academic leaders in the Jordanian Ministry of Education about the significance of educational media. Having much awareness in this regard shall contribute to preserving the customs, traditions, and cultural identify. Therefore, the present study aimed to offer a proposed educational-administrative vision for activating the role of educational media in Jordanian secondary public schools in addressing the intellectual and cultural challenges.

\section{Statement of the Problem}

The researchers conducted this study due to the minor role of educational media in addressing the intellectual and cultural challenges. They conducted this study due to the minor role of educational media in promoting awareness among the future generations about the future challenges. They conducted this study because it is necessary to offer a strategy for activating the role of educational media in the Jordanian Ministry of Education as it's suggested by Hawamdeh (2016). The latter researcher offered such a strategy.

The researchers conducted this study due to having challenges hindering the educational system from doing its functions effectively. Such challenges include: globalism (Al Eid, 2018). They conducted this study because educational media in schools has been showing a poor performance in educating the future generations and instilling values within them. Due to such poor performance, the Western media challenges shall find it very easy to invade the Arab Islamic world in cultural areas. Such invasion aims at eliminating the Arab culture, traditions, values and customs. To fight against such invasion, awareness must be promoted among educational leaders about the significance of educational media. To fight against such invasion, the role of educational media must be activated. To activate the latter role, researchers must propose educational-administrative vision for activating the role of educational media in Jordanian secondary public schools in addressing the intellectual and cultural challenges. In this regard, the problem of the present study is represented in the following question: (What is the reality of the role of educational media in Jordanian secondary public schools in addressing the intellectual and cultural challenges faced by students?)

\section{The Study's Questions:}

The present study aimed to explore the reality of the role of educational media in Jordanian secondary public schools in addressing the intellectual and cultural challenges faced by students. It also aimed to offer a proposed educational-administrative vision for activating the role of educational media in Jordanian secondary public schools in addressing the intellectual and cultural challenges. To be more specific, it aimed to answer the following questions:

Q.1. What is the reality of the role of educational media in Jordanian secondary public schools in addressing the intellectual and cultural challenges facing students from the principals' perspective?

Q.2. What is the proposed educational-administrative vision for activating the role of educational media in Jordanian secondary public schools in addressing the intellectual and cultural challenges?

Q.3. Is the aforementioned proposed educational-administrative applicable from the perspective of experts and specialists?

\section{The Study's Objectives:}

This study aimed to:

-Explore the reality of the role of educational media in Jordanian secondary public schools in addressing the intellectual and cultural challenges facing students from the principals' perspective.

-Offer a proposed educational-administrative vision for activating the role of educational media in Jordanian secondary public schools in addressing the intellectual and cultural challenges.

-Explore the applicable the aforementioned proposed educational-administrative in addressing the intellectual and cultural challenges from the experts' perspective.

\section{The Study's Significance:}

The significance of the present study arises from the significance of the role of educational media in addressing the intellectual and cultural challenges faced by students during the contemporary ages. It arises from the significance of the role of educational media in strengthening the social bonds between the members of the society and meeting the intended educational goals. It arises from the significance of the role of educational media in developing the students' personalities and developing their behaviours. 
The researchers believe that this study is beneficial for:

-The Ministry of Education: The results are beneficial for decision makers at the Ministry. For instance, they enable them to make effective decisions and take effective measures for improving educational media in the Ministry.

-Researchers and graduate students: This study serves as a significant for researchers and graduate students who want to conduct similar studies. It facilitate the process of developing the theoretical framework.

\section{Definition of Terms}

After reviewing the relevant literature and previous studies, the researchers provided definitions for the study's terms below:

-Educational media: It refers to any message transmitted through media in order to educate people, transmit cultural heritage to them and promote belonging among them. It aims at providing people with conceptual knowledge, and developing their skills. It aims at expanding their expertise, modifying their behaviors and promoting specific attitudes among them (Khadr, 2018).

-Intellectual and cultural challenges: They refer to the challenges that emerged during the third millennium and affected the cultural identifies of people negatively. They negatively affected customs' traditions and ideas (AlRaqab, 2007)

\section{The Study's Limits}

The present study was conducted during the second semester of the academic year (2019/2020). It targets the Jordanian public secondary school principals.

\section{Previous Studies:}

Through this part, the researchers presented several studies. Some of those studies are published in Arabic and others are published in English. They shed a light on educational media and the intellectual and cultural challenges that have been facing people. They are ordered from the oldest ones to the latest ones.

Bostrom (2006) aimed to explore the relationship between technological revolution and political changes from one hand and ethical awareness from another hand in educational institutions. They found that there is a relationship between technological revolution and political changes from one hand and ethical awareness from another hand in educational institutions. They found that educational institutions play a major role in reducing the severity of the damages derived from the technological revolution. In addition, educational institutions play a major role in promoting awareness about the way technologies ought to be used. The latter researchers reviewed the literature that shed a light on the impact of technologies and the challenges derived from using technologies.

Al- Amoudi (2009) aimed to shed a light on the reality of educational media and the contributions of eleventh grade female teachers in terms of educational media. He aimed to shed a light on such contributions from the perspective of the female students and academic supervisors in Makkah, Saudi Aarabia. He used a questionnaire to collect data. He adopted a descriptive approach. He selected a sample that consists from 2311 female students and 100 female academic supervisors. The overall mean of the contributions of eleventh grade female teachers in terms of educational media is low from the perspective of the female students and academic supervisors. It is 1.65 when measured from the perspective of the female students. It is 1.88 when measured from the perspective of the female academic supervisors. The latter researcher found that the mean of the reality of educational media is low.

Labs (2014) aimed to shed a light on the relationship between globalization and cultural identity. He aimed to shed a light on the way of preserving the cultural identity. He adopted a historical approach. He also adopted an analytical approach. He proposed a vision for preserving a cultural identify in the light of globalism. The latter vision includes: showing respect for the ones who belong to other cultures and the ones who adopt different values

Cox \& Mcleod (2014) aimed to explore the way of utilizing social media by school principals in the United States for delivering educational messages. Such messages includes the ones that aim at guiding and educating students, teachers and the members of the local community. To meet the intended goals, qualitative approach was adopted and interviews were conducted. Interviews were conducted with 12 school principals. Those principals use social media. The latter researchers found that social media facilitates the process of doing educational tasks. That is because social media facilitates the process of communicating with stakeholders (e.g. school owners, school funders and teachers).

Fedorov \& Levitskaya (2015) aimed to shed a light on the significance of educational media. They aimed to shed a light on the areas in which the role of the educational media must be activated in. They targeted 18 countries. Those countries the United States of America, the United Kingdom, Canada, Australia, New Zealand, Germany, Ireland, Spain, Portugal, Sweden, Finland, Greece, Cyprus, Hungary, Ukraine, Serbia, Turkey, and Russia. The latter researchers adopted a survey-based approach. They used a survey for collecting data. Regarding the areas in which the role of the educational media must be activated in, they include: educational, and religious areas. They found that the role of the educational media must be activated for solving social problems, developing the critical thinking skills of the members of the society and promoting political awareness among them. 
Fatkhova \& Mingazova (2016) aimed to identify the personality traits of the ones adopting extremist ideologies. They aimed to explore the relationship between adopting such ideologies and the use of social media among students in Bashkortostan, Russia. They adopted a descriptive qualitative approach. They used a questionnaire and conducted interviews for collecting data from the sample. The sample consists from 578 secondary school students. It also consists from 5 experts who are specialized in psychology in Bashkortostan. It was found that technological development facilitated the process of communicating with others. However, the misuse of technological in general and social media in particular facilitates the spread of extremist ideologies among people.

Hawamdeh (2016) aimed to propose an educational strategy for activating the role of educational media in the Jordanian Ministry of Education. To meet the intended goals, he used a questionnaire and conducted interviews He found that the mean of the reality of educational media is moderate. He found that there are statistically significant differences between the respondents' attitudes towards the latter reality which can be attributed to gender. The latter differences are for the favor of females. He found that there isn't any statistically significant difference between the respondents' attitudes towards the latter reality which can be attributed to academic qualification.

Al Eid (2018) aimed to propose a vision for activating the role of the Jordanian educational system in addressing the implications of globalism on the Jordanian cultural identity. To meet the intended goals, he used a questionnaire that consists from 68 items. This questionnaire sheds a light on several areas (i.e. the educational system, teachers, curricula and challenges). The study's population consists from all the female and male secondary school teachers who work in Jordanian secondary schools. The latter researcher selected a simple random sample that consists from 2100 female and male teachers. He adopted a developmental descriptive approach. He found that the severity of the challenges hindering the Jordanian educational system from addressing the implications of globalism on the Jordanian cultural identity is high.

Al- Tamimi (2018) aimed to explore the intellectual security level of intermediate school principals in AlRefa'I, Dhi Qar, Iraq. The sample consists from 45 female and male principals. It represents $78 \%$ of the study's population. The researcher adopted a descriptive approach to meet the intended goals. He used a questionnaire that consists from 29 items. This questionnaire sheds a light on four areas (i.e. teachers, parents, students and instructional activities). The researcher checked the validity and reliability of the questionnaire. He found that the the intellectual security level of intermediate school principals in Al-Refa'I, Dhi Qar, Iraq is high from the perspective of those principals. He found that there are statistically significant differences between the respondents' intellectual security which can be attributed to gender for the favor of males.

Al- Hajri (2019) aimed to explore the role of cultural organizations in addressing issues related to intellectual extremism. He targeted the cultural department at the League of Arab States. He used a descriptive analytical approach. He used a survey. He surveyed 110 employees who work at the cultural department at the League of Arab States. Those employees represent 22 countries. Each five employees represent one country only. He found that the latter department works in cooperation with other organizations that are concerned in heritage-related issues. He found that the latter department seeks preserving the heritage of Arab countries and issuing periodical reports that are concerned in culture. He found that the latter department seeks developing strategies that preserve cultural heritage.

\section{Comments on the Aforementioned Studies}

It can be noticed that the aforementioned studies shed a light on concepts related to the subject of the present study. For instance, the studies conducted by Fedorov \& Levitskay (2015) and Hawamdeh (2016) light on educational media. As for the studies of Fatkhova \& Mingazova (2016), Al-Tamimi (2018) and Al-Eid (2018), they shed a light on cultural and intellectual challenges.

The aforementioned studies differ from each other in terms of the population, sample size and the institutions they target. They also differ from each other in terms of the approach, data collection methods, goals and variables. They also differ from each other in terms of data analysis methods and the occupation of the members of the sample.

Reviewing the aforementioned studies assisted the researchers of the present study is determining the study's problem, and approach. It assisted the researchers in determining the measures of carrying out this study. It provided the researchers with much knowledge.

Contrary to the aforementioned studies, the present study sheds a light on the role of the educational media in addressing the cultural and intellectual challenges facing students. Contrary to the aforementioned studies, it aimed to offer a proposed educational-administrative vision for activating the role of educational media in Jordanian secondary public schools in addressing the intellectual and cultural challenges. This vision shall contribute to developing education in Jordan 
10. Methodology:

10.1. The Study's Approach

The researchers adopted a developmental descriptive approach to explore the reality of therole of educational media in Jordanian secondary public schools in addressing the intellectual and cultural challenges faced by students.

\subsection{Population}

The study's population consists from all the Jordanian secondary public schools (i.e. 1227 female and male principals).

\subsection{Sample}

The researchers selected a random stratified sample that consists from 127 female and male principals. Those principals were chosen from 3 provinces in Jordan. 127 secondary public schools were sampled. 54 schools are located in the Northern Province, 33 province are located in the Central Province and 40 schools are located in the Southern Province

\subsection{Instrument}

The researchers developed the questionnaire after reviewing several studies, such as: the studies conducted by Hawamdeh (2016) and Al-Eid (2018). The study of Hawamdeh (2016) sheds a light on the role of educational media and the study of Al-Eid (2018) sheds a light on cultural and intellectual challenges. The researchers developed the questionnaire after consulting several experts who are specialized in educational administration. The questionnaire consists from 30 items. It sheds a light on the reality of the role of educational media in Jordanian secondary public schools in addressing the intellectual and cultural challenges faced by students. It sheds a light on the challenges hindering the educational media in Jordanian secondary public schools from addressing those challenges.

The five point Liket scale was used. It consists from five rating categories. Those categories are: always, often, sometimes, rarely and never. They stand for the following scores respectively: 5, 4, 3, 2 and 1 . To set criteria for classifying means, the following equation was used:

(Interval $=$ the maximum score- the minimum score/ the require number of categories)

Interval $=(5-1) / 3$. Thus, the interval is 1.33 . Thus, the following criteria are used for classifying means.

2.33 or less: Low

2.34- 3.67: Moderate

3.68 or greater: high

\subsection{Validity of the Instrument:}

The researchers checked the content validity of the questionnaire through passing the initial version of the questionnaire to 15 experts. Those experts are specialized in educational leadership and administration. They work at the University of Jordan as faculty members. They were asked to assess the questionnaire in terms of clarity, and relevancy to the goals. They were asked to make suggestions to the questionnaire. The researchers decided to keep the items that are approved by $80 \%$ of the experts. Thus, changes were made to the questionnaire to draft the final version. The latter version consists from 35 items.

\subsection{Reliability of the questionnaire:}

The researchers measured the reliability of the questionnaire through calculating the Cronbach alpha coefficient value of each area of the study's areas. They measured such reliability through calculating the Pearson correlation coefficient values. To calculate the latter values, the questionnaire forms were passed to the members of the exploratory sample. After two weeks, the questionnaire forms were passed again to the members of the exploratory sample. This exploratory sample consists from 30 Jordanian public secondary school principals. The Pearson correlation coefficient values are within the range of (0.95-0.96). Table (1) presents the Pearson correlation coefficient values and the Cronbach alpha coefficient values for the study's areas. 
Table (1): The Pearson correlation coefficient values and the Cronbach alpha coefficient values for the study's areas

\begin{tabular}{|l|l|l|l|}
\hline No. & Area & $\begin{array}{l}\text { The Cronbach alpha } \\
\text { coefficient values }\end{array}$ & $\begin{array}{l}\text { The Pearson correlation } \\
\text { coefficient values }\end{array}$ \\
\hline 1 & $\begin{array}{l}\text { The reality of the role of educational media in } \\
\text { Jordanian secondary public schools in addressing } \\
\text { the intellectual and cultural challenges }\end{array}$ & 0.96 & 0.82 \\
\hline 2 & $\begin{array}{l}\text { The extent of meeting the requirements of } \\
\text { activating the role of educational media in } \\
\text { Jordanian secondary public schools }\end{array}$ & $\begin{array}{l}\text { The obstacles hindering the educational media from } \\
\text { addressing the intellectual and cultural challenges }\end{array}$ & 0.95 \\
\hline 3
\end{tabular}

\subsection{The Study's Variables:}

The present study targets the following variables:

a)-The independent variable: It is represented in the reality of the role of educational media in Jordanian secondary public schools in addressing the intellectual and cultural challenges.

b)- Mediating variables: They are represented in gender and academic qualifications (holders of BA degree, post graduate degree or vocational diploma).

c)- The dependent variable: It is represented in the respondents' attitudes towards the role of educational media in Jordanian secondary public schools in addressing the intellectual and cultural challenges

\section{Results and Discussion:}

This part presents the study's results

\subsection{Results and discussion related to the first question:}

Q.1. What is the reality of the role of educational media in Jordanian secondary public schools in addressing the intellectual and cultural challenges facing students from the principals' perspective?

To answer this question, means and standard deviations are calculated and presented below in table (2):

Table (2): The means and standard deviations for exploring the degree to which the role of the educational media in Jordanian secondary public schools is activated in addressing the intellectual and cultural challenges facing students from the principals' perspective

\begin{tabular}{|l|l|l|l|l|l|}
\hline No. & Area & Mean & Std. & Rank & Level \\
\hline 1 & $\begin{array}{l}\text { The reality of the role of educational media in Jordanian secondary } \\
\text { public schools in addressing the intellectual and cultural challenges }\end{array}$ & 3.07 & 1.12 & 1 & Moderate \\
\hline 2 & $\begin{array}{l}\text { The extent of meeting the requirements of activating the role of } \\
\text { educational media in Jordanian secondary public schools }\end{array}$ & 2.38 & 0.96 & 2 & Moderate \\
\hline 3 & $\begin{array}{l}\text { The obstacles hindering the educational media from addressing the } \\
\text { intellectual and cultural challenges }\end{array}$ & 2.32 & 0.88 & 3 & Low \\
\hline & Total & 2.83 & 0.94 & & Moderate \\
\hline
\end{tabular}

Based on table (2), the means are within the range of (2.32-3.07). The mean of (the reality of the role of educational media in Jordanian secondary public schools in addressing the intellectual and cultural challenges) is 3.07 which is moderate and ranked first. The mean of the (extent of meeting the requirements of activating the role of educational media in Jordanian secondary public schools) is 2.38 which is moderate and ranked second. The mean of the (obstacles hindering the educational media from addressing the intellectual and cultural challenges) is 2.32 which is low and ranked third. As for the overall mean, it is 2.83 . This indicates that the degree to which the role of the educational media in Jordanian secondary public schools is activated in addressing the intellectual and cultural challenges is moderate.

First: The reality of the role of educational media in Jordanian secondary public schools in addressing the intellectual and cultural challenges facing students from the principals' perspective

The researchers calculated the relevant means and standard deviations for exploring the reality of the role of educational media in Jordanian secondary public schools in addressing the intellectual and cultural challenges. Table (3) presents the means and standard deviations related to this reality 
Table (3): The reality of the role of educational media in Jordanian secondary public schools in addressing the intellectual and cultural challenges facing students from the principals' perspective

\begin{tabular}{|c|c|c|c|c|c|}
\hline No. & Items & Mean & Std. & Rank & Level \\
\hline \multicolumn{6}{|c|}{ Educational media in Jordanian secondary public schools } \\
\hline 5 & $\begin{array}{l}\text { Contributes to promoting awareness among students about the } \\
\text { implications of globalism }\end{array}$ & 3.28 & 1.22 & 1 & Moderate \\
\hline 6 & Contributes to developing students' problem solving skills & 3.17 & 1.23 & 2 & Moderate \\
\hline 9 & $\begin{array}{l}\text { Contributes to developing students' thinking in a manner that } \\
\text { enables them to address (intellectual and cultural challenges). }\end{array}$ & 3.17 & 1.22 & 2 & Moderate \\
\hline 4 & $\begin{array}{l}\text { Contributes to encouraging students to adapt with changes in } \\
\text { various aspects of life }\end{array}$ & 3.15 & 1.27 & 4 & Moderate \\
\hline 15 & $\begin{array}{l}\text { Contributes to promoting knowledge among students about the most } \\
\text { significant social problems }\end{array}$ & 3.12 & 1.28 & 5 & Moderate \\
\hline 13 & $\begin{array}{l}\text { Contributes in providing people with knowledge about the heritage } \\
\text { of the civilization. }\end{array}$ & 3.12 & 1.19 & 5 & Moderate \\
\hline 12 & $\begin{array}{l}\text { Offers programs that contribute to the development of students' } \\
\text { personalities }\end{array}$ & 3.10 & 1.28 & 7 & Moderate \\
\hline 7 & $\begin{array}{l}\text { Contributes to fighting against the cultural factors that may } \\
\text { negatively affect their values. }\end{array}$ & 3.09 & 1.33 & 8 & Moderate \\
\hline 3 & $\begin{array}{l}\text { Improves students' understanding for local, regional and global } \\
\text { issues }\end{array}$ & 3.07 & 1.25 & 9 & Moderate \\
\hline 10 & $\begin{array}{l}\text { Contributes to developing students' competency in using Modern } \\
\text { Standard Arabic }\end{array}$ & 3.06 & 1.34 & 10 & Moderate \\
\hline 14 & Encourages students to adopt healthy habits & 2.98 & 1.33 & 11 & Moderate \\
\hline 2 & $\begin{array}{l}\text { Contributes to improving students' understanding for the global } \\
\text { culture. }\end{array}$ & 2.96 & 1.27 & 12 & Moderate \\
\hline 8 & $\begin{array}{l}\text { Presents the national heritage through using multimedia. It may } \\
\text { present the national heritage through stories and plays }\end{array}$ & 2.88 & 1.29 & 13 & Moderate \\
\hline 1 & $\begin{array}{l}\text { Contributes to improving students' understanding for the local } \\
\text { culture. }\end{array}$ & 2.86 & 1.19 & 14 & Moderate \\
\hline & Overall & $\mathbf{3 . 0 7}$ & 1.12 & & Moderate \\
\hline
\end{tabular}

Based on table (3), the overall mean is 3.07 which is moderate. Thus, the reality of the role of educational media in Jordanian secondary public schools in addressing the intellectual and cultural challenges facing students is moderate from the principals' perspective. The means of all items in table (3) are moderate. They are within the range of $(2.86-3.28)$. The mean of statement (5) is 3.28 which is ranked first. The latter statement states the following: (Educational media in Jordanian secondary public schools contributes to promoting awareness among students about the implications of globalism). The mean of statement (6) is ranked second. The latter statement states the following: (Educational media in Jordanian secondary public schools contributes to developing students' problem solving skills). The mean of statement (1) is ranked last. The latter statement states the following: (Educational media in Jordanian secondary public schools contributes to improving students' understanding for the local culture).

The latter results may be attributed to the poor infrastructure in Jordanian secondary public schools. They may be attributed to having inadequate number of employees working in the field of educational media. They may be attributed to the poor coordination between educators and plan developers. There must more coordination between them to develop strategies and programs that maintain the original Arab culture. They are consistent with the result concluded by Hawamdeh (2016) who found that the mean of the reality of educational media is moderate. They are inconsistent with the results concluded by Al- Amoudi (2009) who found that the mean of the reality of educational media is low.

Second: The extent of meeting the requirements of activating the role of educational media in Jordanian secondary public schools.

Means and standard deviations are calculated to explore the extent of meeting the requirements of activating the role of educational media in Jordanian secondary public schools. They are presented in table (4) 
Table (4): Means and standard deviations are calculated to explore the extent of meeting the requirements of activating the role of educational media in Jordanian secondary public schools

\begin{tabular}{|l|l|l|l|l|l|}
\hline No. & Items & Mean & Std. & Rank & Level \\
\hline 23 & $\begin{array}{l}\text { Teachers are provided with training courses about educational } \\
\text { media }\end{array}$ & 2.54 & 1.16 & 1 & Moderate \\
\hline 16 & $\begin{array}{l}\text { Programs are broadcasted through media in the aim of promoting } \\
\text { principles that aim at preserving the cultural identity of people. That } \\
\text { is done through stories, movies and role models. }\end{array}$ & 2.45 & 1.11 & 2 & Moderate \\
\hline 20 & $\begin{array}{l}\text { Programs are broadcasted through media in the aim of promoting } \\
\text { religious principles and values among students }\end{array}$ & 2.38 & 1.09 & 3 & Moderate \\
\hline 19 & $\begin{array}{l}\text { Programs are broadcasted through media in the aim of promoting a } \\
\text { culture that is based on co-existing with the ones who are different }\end{array}$ & 2.36 & 1.09 & 4 & Moderate \\
\hline 17 & $\begin{array}{l}\text { Programs are broadcasted through media in the aim of promoting } \\
\text { awareness among students about the negative cultural, health and } \\
\text { social impacts of drugs. }\end{array}$ & 2.35 & 1.14 & 5 & Moderate \\
\hline 21 & $\begin{array}{l}\text { Programs are broadcasted through media in the aim of promoting } \\
\text { ethics among students }\end{array}$ & 2.34 & 1.12 & 6 & Moderate \\
\hline 18 & $\begin{array}{l}\text { Programs are broadcasted through media in the aim of promoting a } \\
\text { dialogue-based culture among students }\end{array}$ & 2.34 & 1.14 & 6 & Moderate \\
\hline 22 & $\begin{array}{l}\text { Programs are broadcasted in standard Arabic language through } \\
\text { media. }\end{array}$ & 2.34 & 1.15 & 6 & Moderate \\
\hline & Overall & 2.38 & 0.96 & & Moderate \\
\hline
\end{tabular}

Based on table (4), the extent of meeting the requirements of activating the role of educational media in Jordanian secondary public schools is moderate. That is because the overall mean is 2.38 . The means in table (4) are within the range of $2.54-2.34$. The mean of statement (23) is 2.54 which is moderate and ranked first. The latter statement states the following: (Teachers are provided with training courses about educational media). The latter result is attributed to the significance of providing in-service and pre-service teachers with training courses. For instance, providing teachers with training courses shall enable them to keep up with the latest developments related to curricula, and media.

The mean of statement (23) is 2.45 which is moderate and ranked second. The latter statement states the following: (Programs are broadcasted through media in the aim of promoting principles that aim at preserving the cultural identity of people. That is done through stories, movies and role models). The latter result is attributed to the significance of promoting positive values that regulate the social aspects of life. Stories, movies and role models are used because they have the greatest impacts on students' personalities.

The mean of statement (22) is 2.34 which is moderate and ranked last. The latter statement states the following: (Programs are broadcasted in standard Arabic language through media). The latter result indicate that the Jordanian society is still keen on using standard Arabic language.

Third: The obstacles hindering the educational media in Jordanian secondary public schools from addressing the intellectual and cultural challenges

Means and standard deviations are calculated to identify such obstacles. They are presented in table (5): 
Table (5): The obstacles hindering the educational media in Jordanian secondary public schools from addressing the intellectual and cultural challenges

\begin{tabular}{|c|c|c|c|c|c|}
\hline No. & Items & Mean & Std. & Rank & Level \\
\hline 25 & $\begin{array}{l}\text { Teachers have poor skills in organizing school activities that aim at } \\
\text { meeting the goal of educational media }\end{array}$ & 2.48 & 1.09 & 1 & Moderate \\
\hline 27 & $\begin{array}{l}\text { The standard examination system negatively affects the school } \\
\text { media activities. }\end{array}$ & 2.47 & 1.01 & 2 & Moderate \\
\hline 29 & $\begin{array}{l}\text { There is much contradiction between the school media culture and } \\
\text { the culture that is promoted through global TV channels. }\end{array}$ & 2.35 & 1.05 & 3 & Moderate \\
\hline 31 & $\begin{array}{l}\text { The number of employees who work in the field of educational } \\
\text { media is low }\end{array}$ & 2.34 & 1.08 & 4 & Moderate \\
\hline 28 & $\begin{array}{l}\text { The extent of using educational media by teachers for meeting } \\
\text { educational goals is low }\end{array}$ & 2.33 & 1.07 & 5 & Low \\
\hline 30 & $\begin{array}{l}\text { There is inadequate coordination between educators and the ones } \\
\text { working in the media field in terms of broadcasting pre-planned } \\
\text { programs for developing children's capabilities and maintaining the } \\
\text { cultural identity }\end{array}$ & 2.31 & 1.07 & 6 & Low \\
\hline 34 & Curricula don't promote the principles of educational media. & 2.28 & 1.16 & 7 & Low \\
\hline 24 & $\begin{array}{l}\text { There isn't much awareness among students' parents about the } \\
\text { significance of school media activities. }\end{array}$ & 2.28 & 1.10 & 7 & Low \\
\hline 26 & $\begin{array}{l}\text { There isn't adequate time for carrying out media-related activities in } \\
\text { schools }\end{array}$ & 2.27 & 1.07 & 9 & Low \\
\hline 35 & $\begin{array}{l}\text { The material broadcasted through educational media is selected and } \\
\text { broadcasted in a non-systematic manner }\end{array}$ & 2.24 & 1.11 & 10 & Low \\
\hline 32 & The powers granted to the educational media department are limited & 2.24 & 1.11 & 10 & Low \\
\hline 33 & $\begin{array}{l}\text { The financial support dedicated for activating the role of educational } \\
\text { media is inadequate }\end{array}$ & 2.24 & 1.15 & 10 & Low \\
\hline & Overall & 2.32 & 0.88 & & Low \\
\hline
\end{tabular}

Based on table (5), the severity of the obstacles hindering the educational media in Jordanian secondary public schools from addressing the intellectual and cultural challenges is low. That is because the overall mean is 2.32 . The mean of statement (25) is 2.48 which is moderate and ranked fast. The latter statement states the following: (Teachers have poor skills in organizing school activities that aim at meeting the goal of educational media).

The mean of statement (27) is 2.47 which is moderate and ranked second. The latter statement states the following: (The standard examination system negatively affects the school media activities). The mean of statement (33) is 2.32 which is low and ranked last. The latter statement states the following: (The financial support dedicated for activating the role of educational media is inadequate).

Results related to the second question:

Q.2. What is the proposed educational-administrative vision for activating the role of educational media in Jordanian secondary public schools in addressing the intellectual and cultural challenges?

To answer this question, the proposed vision is presented below:

Title of the vision: (A proposed educational-administrative vision for activating the role of educational media in Jordanian secondary public schools in addressing the intellectual and cultural challenges)

\section{Introduction:}

Education plays a major role in the advancement of people and societies. It plays a major role due to having many political, economic, social, cultural, and technological developments. It enables one to adapt with the customs and traditions of the society he/she belong to. It contributes to developing one's personality. It contributes to developing one in physical, cognitive, and intellectual areas. It contributes to developing one's skills. It is provided by family, kindergartens, schools, universities, worship houses, clubs, and media channels. Due to the significant role of media, media today enables one to have knowledge about the reality. In this regard, educational media plays a major role. Thus, the role of educational media must be activated by educational media leaders in order to meet the intended educational goals. It must be activated to develop people's skills and expand their knowledge. In order to activate the role of educational media, researchers must propose a vision for ensuring such activation. This vision must activate the role of educational media in addressing the intellectual and cultural challenges)

Definition of the Proposed Vision:

This vision involves a set of strategies, guidelines and steps that aim at enabling educational leaders to activate the role of educational media in addressing the intellectual and cultural challenges.

The mission of the vision

This vision aims at enabling the educational media to show excellence ineducating people. It aims at developing 
the educational media and makes it based on global standards, and social values. That shall contribute to the development of Jordan. It is necessary to develop Jordan in the light of having intellectual and cultural challenges. Such challenges include: globalism, intellectual extremism, information revolution and decline in ethics.

\section{Limitations of the vision:}

This vision involves a set of procedures and operations that aim at reaching specific outcomes. It aims at enabling educational leaders in the Ministry of Education to meet the goals of educational media.

\section{Principles of the visions}

1)- The proposed vision is based on the Jordanian constitution and the heritage of the Islamic Arab civilizations.

It's educational on the Jordanian experience

2)- The proposed vision was developed based on the future and current needs of the Jordanian society and the requirements of achieving comprehensive development in Jordan

3)-The proposed vision aims at ensuring that all students get equal opportunities in terms of access to educational services and use of ICTs.

4)-The proposed vision aims at ensuring that educational media employs the best educational methods for developing students' learning skills. It aims at developing such skills in accordance with specific criteria.

5)- The proposed vision aims at developing the policies, decisions and plan related to educational media.

The categories that shall benefit from the vision:

The proposed vision is beneficial for the makers of decisions related to educational media. It is beneficial for the developers of plans related to educational media. It is beneficial for principals. It is beneficial for teachers. For instance, it enables teachers to develop their educational media-related skills and classroom management skills. It enables teachers to develop their skills in interacting with students. It enables teachers to develop themselves professionally in a manner that meets the intended educational goals.

\section{The elements of the vision}

This visions aims at providing the concerned educational leaders with support, and guidance in all the stages of broadcasting educational media. It aims to do that through following specific procedures. It consists from several instruments that are related to

a)- The reality of the role of educational media in Jordanian secondary public schools in addressing the intellectual and cultural challenges

b)- The requirements of activating the role of educational media in Jordanian secondary public schools

c)- The obstacles hindering the educational media from addressing the intellectual and cultural challenges

\section{The way of implementing the proposed vision}

This vision is clear and simple. It involves a set of procedures that aim at activating the role of educational media in Jordanian secondary public schools in addressing the intellectual and cultural challenges. It provides specialists with instruments that enable them to assess the reality of educational media, and identifying the shortcomings and strengths in it. It enables specialists to address such shortcomings.

\section{Illustration for the way of utilizing thevision:}

The vision should be utilized to improve the capability of the workers in the educational media department at the Ministry of Education in doing their tasks. It should be utilized to improve the capability of the principals and teachers in doing their tasks. Thus, it improves the outcomes of educational institutions in order to achieve excellence and entrepreneurship.

\section{The objectives of the vision}

This vision aims at:

a) Determining the educational media-related training needs of the staff working in educational institutions

b) Developing the educational media institutions

c) Improving the performance of educational media

d) Promoting a culture that is based on cooperation

\section{The instruments used for meeting the gaols of the vision}
A) Performance assessment checklist
B) A checklist for determining the needs
C) Review instrument
D) Brainstorming

Methods and Procedures:

1)-Effective administrative leadership: If one is an educational leader, he must visit the institutions affiliated with the Ministry of Education. He must visit the local community and the educational media in the latter ministry. That is because the educational leader must meet teachers, and other workers in the educational field. Through reviewing the records, the educational leader must have knowledge the administrative staff and teachers in schools and the workers in the educational field. He must take notes during his field visits in order to make developments. 2)- The educational leader must get acquainted with the employees in the educational media field and teachers. That is done through holding a preliminary meeting. Through this meeting, he must take notes about the 
weaknesses in the current reality and listen well to each speaker. Through this meeting, he must act wisely and show that he has a strong personality. He must make the attending staff feel that he has a strong personality.

3)- The educational leader must determine the strengths and weaknesses of the educational media institutions and schools. He must identify the issues that must be addressed by educational media institutions. Such issues include: financial issues and curricula-related issues. He must determine the priorities. He must classify such issues in accordance with their priorities

4)- The educational leader must hold a second meeting. In this meeting, the employees in the educational media field and educational staff in school shall be attending. Through this meeting, the educational leader must let people become familiar with his personality as an educational leader. He must identify his priorities. He must avoid addressing the shortcoming during the beginning of the meeting. He address all the issues that are listed in the meeting record. He must ask the attendants to make suggestions and listen them to attendants well.

5)- The educational leader must carry out administrative and technical staff. He must keep assessing the performance of employees throughout the whole semester. Such assessment shall enable the leader to identify the weaknesses and strengths of employees. It shall enable the leaders to take measures for addressing such weaknesses. Such measures may include holding training courses or workshops.

\section{Important tips for applying this vision effectively:}

-The tasks that were assigned to teams must be done. Control must be enforced on teams in this regard

-The ones who show poor performance must be informed about that in order for them to make changes

-There must be a fixed assessment system for assessing employees in a fair manner. This system must the take the employees' personalities and psychological status into consideration

-The educational leader must treat all people in a fair and respectful manner. He must ensure that all employees enjoy all their rights.

-The educational leader must determine the dates on which employees shall be assessed.

-The educational leader must ensure that the infrastructure in all schools is good. Such infrastructure includes: connection to internet, facilities and equipment. The educational leader must ensure that the ones who work in the educational media field are provided with the needed resources. He must ensure that the latter employees are qualified. He must take the required measures on time for addressing any shortcoming.

-The educational leader must ensure that all employees have electronic access to the code of ethics. He must ensure that all employees have knowledge about their right and duties in schools. He must distribute pamphlets about ethics to all employees in school (e.g. a pamphlet titled the constitution of ethics).

\section{Results related to the third question:}

Q.3. Is the aforementioned proposed educational-administrative applicable from the perspective of experts and specialists?

To answer this question, the initial version of the vision was passed to several experts. Those experts include: experts in media, experts in educational administration and experts in pedagogy. They were asked to assess the vision in terms of effectiveness in addressing the intellectual and cultural challenges. They were asked to make changes to the vision. They made language-related changes. They suggested that the vision is effective and applicable.

\section{Recommendations:}

In the light of the results, the researchers recommend:

1) Implementing the proposed vision in Jordanian public secondary schools.

2) Drafting a philosophy to be adopted by educational media institutions. This philosophy should enable those institutions to keep up with the latest technological and technical developments. It must aim at prompting knowledge about the cultural identify

3) Increasing the coordination between media institutions and educational institutions. Through such cooperation, educational institutions must develop plans and media institutions must provide instruments and methods for implementing such plans.

4) Holding training courses for the ones working in the field of media, teachers, students and other employees who work in the educational field. Such courses must aim at activating the role of educational media in addressing the intellectual and cultural challenges. They must aim at activating the role of educational media in meeting the intended goals.

5) Adding content about educational media and intellectual and cultural challenges through the citizenship education curricula. Such curricula must provide students with knowledge about the mechanisms to be adopted for addressing such challenges

\section{References}

- Al-Amoudi, Hana (2009). The reality of the contributions of the first secondary school teachers in media education from the viewpoint of female students and supervisors in educational studies in the city of 
Makkah Al-Mukarramah, unpublished master's thesis, Umm Al-Qura University, Makkah Al-Mukarramah, Kingdom of Saudi Arabia.

- $\quad$ Al-Hajri, Muhammad Saad (2019). The Role of Cultural Aid Organizations in Facing Issues of Intellectual Extremism: An Applied Study on Culture Management at the League of Arab States, Journal of Educational Sciences, 27 (1), 75-49.

- Al-Harthy, Zaid (2008), the contribution of the educational media in achieving intellectual security among high school students in Makkah from the point of view of principals, school agents and educational supervisors, unpublished Master Thesis, Umm Al-Qura University, Makkah Al-Mukarramah, Saudi Arabia

- Al-Raqab, Saeed (2007), Cultural Identity in Contemporary Arab Educational Thought and Future Challenges, Amman: Jaffa Scientific House.

- Al-Rifai, Aqeel (2008). Educational media. Cairo: The New University House.

- Al-Sarhani, Najwa Ahmed (2014). A proposed educational strategy for Saudi universities in facing cultural challenges and enhancing national affiliation with their students, unpublished doctoral thesis, University of Jordan, Amman, Jordan.

- Al-Sharif, Abdulaziz (2014) .Media and Education. Amman: affa House for Publishing and Distribution.

- Al-Tamimi, Raed and Ramadan, Hussein (2018). The extent of school principals practicing intellectual security to confront the phenomenon of extremism in the middle stage from the viewpoint of the principal themselves. International Journal of Research in Educational Sciences 1(3),386-342.

- $\quad$ Bosfor, Hassan, Amer, Tareq \& Mohammad, Rabea (2011). Educational Media: Its Concept, Philosophy and Goals. Cairo: Teeba Foundation for Publishing and Distribution.

- Bostrom, N (2006), Technological Revolutions: Ethics And Policy In The Dark, Pupli Shedin Nanoscale: Issues And Perspectives For The Nano Centuury, Cameron And M. Ellen Mitchell.

- $\quad$ Cox, D. \&Mcleod, M. (2014), Social Media Strategies For School Principals,Nassp Bulletin, 98(1), 5-25.

- $\quad$ Eid, Lana Khalil (2018), a suggested role for the Jordanian educational system to counter the effects of cultural globalization on Jordanian cultural identity, unpublished doctoral thesis, University of Jordan, Amman, Jordan.

- $\quad$ Fatkhova, R ;Mingazova, D. (2016). Diagnostics of Teenagers Disposition To Destructive Communication as Way Of Youth Extremism Prevention. Global Media Journal, American Edition,1(1):5-45.

- Feast, Warm (2014). The cultural dimension of globalization and its impact on the cultural identity of Arab youth, The Generation of Human and Social Sciences Journal. 2, 25-9.

- Fedorov, A.\&Levitskaya, A. (2015), The Framework Of Media Education And Media Criticism in The Contemporary World: The Opinion Of International Experts, Media Education Research Journal, 45(1), $107-117$

- Hawamdeh, Maher (2016), a proposed educational strategy to activate the role of educational media in the Jordanian Ministry of Education, unpublished doctoral thesis, University of Jordan, Amman, Jordan.

- $\quad$ Khadr, Wafaa Al-Sayed (2018), a new vision in educational media, Cairo: Dar Al-Fajr for publication and distribution.

- Labes, S.(2014). Globalization And Cultural Identity Dilemmas. Centre For European Studies CES Working Papers. 6(1), 33-38.

- $\quad$ Madkour, Ali (2003), Education and Culture of Technology, Cairo: Dar Al-Figr Al-Arabi.

- Najm, Taha (2004). Sociology of knowledge is a study of consciousness and ideology. Alexandria: University Knowledge House.

- Rajab, Muhammad Ali (2015). Modern educational media. Amman: Dar Al-Moataz for Publishing and Distribution. 